(3)

Volume 20, 2017

\title{
IMPROVING INFORMATION TECHNOLOGY CURRICULUM LEARNING OUTCOMES
}

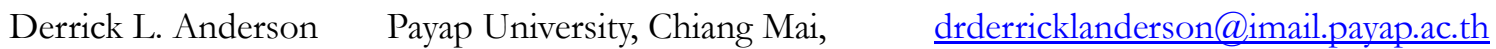
Thailand

\begin{abstract}
Aim/Purpose Information Technology students' learning outcomes improve when teaching methodology moves away from didactic behaviorist-based pedagogy toward a more heuristic constructivist-based version of andragogy.

Background There is a distinctive difference, a notable gap, between the academic community and the business community in their views of the level of preparedness of recent information technology program graduates. An understanding of how Information Technology curriculum is developed and taught along with the underpinning learning theory is needed to address the deficient attainment of learning outcomes which lies at the heart of this matter.
\end{abstract}

Methodology The case study research methodology has been selected to conduct this empirical inquiry facilitating an in depth exploration within its real-life context. The subject of analysis is two Information Technology classes which are composed of a combination of second year and third year students; both classes have six students, the same six students.

Contribution It is the purpose of this research to show that the use of improved approaches to learning will produce more desirable learning outcomes.

Findings The results of this inquiry clearly show that the use of the traditional behaviorist based pedagogic model to achieve college and university IT program learning outcomes is not as effective as a more constructivist based andragogic model.

Recommendations Instruction based purely on behaviorism or constructivism does a disservice to for Practitioners the typical college and university level learner. The correct approach lies somewhere in between; the most successful outcome attainment will be the product of incorporating the best of both.

Impact on Society Instructional strategies produce learning outcomes; learning outcomes demonstrate what knowledge has been acquired. Acquired knowledge is used by students as they pursue professional careers and other ventures in life.

Future Research Learning and teaching approaches are not "one-size-fits-all" propositions; different strategies are appropriate for different circumstances and situations. Additional research should seek to introduce vehicles that will move learners away

Accepting Editor Raafat Saadé | Received: November 29, 2016 | Revised: March 15, 2017 | Accepted: May 8, 2017.

Cite as: Anderson, D. L. (2017). Improving information technology curriculum learning outcomes. Informing Science: the International Journal of an Emerging Transdiscipline, 20, 119-131. Retrieved http://www.informingscience.org/Publications/3746

(CC BY-NC 4.0) This article is licensed to you under a Creative Commons Attribution-NonCommercial 4.0 International License. When you copy and redistribute this paper in full or in part, you need to provide proper attribution to it to ensure that others can later locate this work (and to ensure that others do not accuse you of plagiarism). You may (and we encourage you to) adapt, remix, transform, and build upon the material for any non-commercial purposes. This license does not permit you to use this material for commercial purposes. 
from one the traditional methodology that has been used throughout much of their educational careers to an approach that is better suited to equip them with the skills necessary to meet the challenges awaiting them in the professional world.

Keywords learning outcomes, pedagogy, andragogy, behaviorism, constructivism, learning theory, instructional strategy

\section{INTRODUCTION}

"Woefully unprepared" is how David E. Boyes of Sine Nomine Associates portrays the recent college graduates he encounters applying for employment with his technology consulting company (Fischer, 2013). His organization, Sine Nomine Associates, works with several high-tech companies including industry leaders Cisco and IBM. His opinion is shared by several other members of the information technology business community; the evidence of this concurrence is verified in the findings of a joint research project conducted by The Chronicle and American Public Media's Marketplace ("The role of higher education," 2012).

The Chronicle of Higher Education and America's Public Media's Marketplace ("The role of higher education," 2012) research project conducted an online survey of three hundred eighteen (318) business executives and hiring managers whose organizations have at least twenty five (25) employees. Each reports that twenty five per cent $(25 \%)$ or more of their new hires hold either an associate degree from a two-year college or a bachelor's degree from a four-year college or university. Half of those surveyed said they had trouble finding recent graduates qualified to fill positions in their company or organization. Fifty eight per cent $(58 \%)$ of the respondents think improvements are needed to ensure that graduates gain the skills and knowledge needed to succeed in entry-level positions in their companies. An even larger proportion, sixty four per cent (64\%), think that improvements are necessary if graduates are to have the skills and knowledge needed to be successful within their company.

There is a distinctive difference, a notable gap, between the academic community and the business community in their views of the level of preparedness of recent information technology program graduates. The academic community believes that, after completing a program whose curriculum follows the guidelines established by the Institute of Electrical and Electronics Engineers (I.E.E.E.) and the Association of Computing Machinery (A.C.M.), a graduate is thoroughly prepared to enter the IT workforce. The business community feels that today's college graduates are not particularly well prepared to achieve the learning outcomes that they view as important. Mr. Boyes finds that it is fundamental abilities that recent graduates lack, like how to analyze large amounts of data or construct a cogent argument: "It's not a matter of technical skill," he says, "but of knowing how to think" (Fischer, 2013). While most other employers surveyed agree that new hires had the right technical know-how for the job, they complained that colleges weren't adequately preparing students in decision-making, analytical skills and research skills. Again, the majority of employers feel that colleges and universities must make improvements to ensure graduates' workplace success ("The role of higher education," 2012).

The demands of potential employers for changes in academic programs that better prepare graduates for employment in their organizations tends not to go over well with academics who look down on any instruction perceived as vocational. Higher education is meant to educate broadly, not train narrowly, most believe, "its business that's asking too much". A disagreeing Richard D. Stephens of the Boeing Corporation shares his opinion stating, "To expect business to bring graduates up to speed ... that's too much to ask" (Fischer, 2013). On-the-job preparation no longer makes economic sense to many companies. "Once upon a time, 'trainee' used to be a common job title," notes Philip D. Gardner, director of the Collegiate Employment Research Institute at Michigan State University. "Now companies expect everyone, recent graduates included, to be ready to go on Day One" (Fischer, 2013). 
How can the vantage points of these two aggregations be so diametrically opposed? How can the two have such dissimilar interpretations when examining the same circumstance? The problem is one of perception. Julian L. Alssid, of the nonprofit Workforce Strategy Center, says that although business and higher education may use the same language, it doesn't always have the same meaning (Fischer, 2013). Are the curriculum standards established by academicians out of touch with the needs of the IT industry? Educators often think of competencies "in a purely academic context", while employers want "book smarts to translate to the real world." "It's a matter of how to apply that knowledge," Alssid says (Fischer, 2013). The fact is that each group is entrenched in their own ideological positions; only the symptoms receive attention and the root cause of the problem is not being addressed.

Can changing the learning theory approach improve outcomes? Will these improved learning outcomes address the concerns of the business community? To satisfy the request of employers, college, and university, Information Technology programs must produce graduates possessing analytical skills as well as familiarity with the foundations of information technology and computer science. It is, therefore, imperative that learners possess critical thinking skills if the desired learning outcomes are to be successfully achieved. The ability to move out of the theoretical realm into the world of practical application is very much dependent on the ability to think critically. This is an area that is in need of improvement and can benefit tremendously if the appropriate adjustments are made.

A more informed understanding of how Information Technology curriculum is developed and taught is at the heart of the perception of inadequate preparation; the underpinning learning theory is directly responsible for the resulting deficient learning outcomes. To do this requires examining how learner outcomes can be improved by making the appropriate modifications and rethinking the methodologies being used in the design and delivery of these programs. It is important to understand that learning outcomes demonstrate what knowledge a student has acquired; these outcomes are the direct result of the instructional strategy and techniques teachers use to facilitate students achieve these objectives. Instructional strategies are driven by learning theory, the conceptual frameworks in which knowledge is absorbed, processed, and retained during learning. Information Technology students' learning outcomes improve when teaching methodology moves away from didactic behaviorist-based pedagogy toward a more heuristic constructivist-based version of andragogy.

\section{LITERATURE REVIEW}

Students come from varied backgrounds; they hail from different countries, they were reared in different cultures, and they live in different socio-economic environments. This diversity contributes to a learning situation in which the participants have a wide range of capabilities. These differences also create challenges in the creation of curriculum; some common frame of reference is necessary. Observed behavior demonstrates that, though many differences and distinctions exist between students, one commonality is shared by the majority, if not by all. This shared trait is what Jim Scrivener, the distinguished Head of Teacher Training for International House and ARELS Frank Bell Prize award winning author, refers to as 'jug and mug' education (Boumová, 2008). Students come to class and listen to the teacher without interruption, without any dialog or interaction even when prompted to do so. Scrivener clarifies the meaning of this by explaining that knowledge is poured from one receptacle, the teacher, into an empty one, the student. This lack of student interaction is found to be characteristic of traditional teaching approaches and methodologies. The students' only required contribution to the learning process is to be in class and listen attentively.

This classroom behavior implies that these students are products of educational systems that employ traditional approaches to teaching. In these systems, the approach to education is very much "teacher-centric". According to Dr. Abdullah Kuzu, Assistant Professor of Curriculum Theory, Teaching Methods, Teacher Education at Anadolu University, the basis of this axiom is that the "traditional view of education is that teachers serve as the source of knowledge while learners serve as passive receivers" (Boumová, 2008). In his book, Communicative Language Teaching Today, Jack C. Richards 
(2006) highlights that in the traditional methodology "learning was very much seen as under the control of the teacher". "Being in a class in the presence of a teacher and 'listening attentively' is [...] enough to ensure that learning will take place", adds Scrivener (Boumová, 2008).

Traditional education is based on a combination of two schools of thought, pedagogy and behaviorism. Together they are referred to as behaviorist pedagogy. From a behaviorist perspective, the transmission of information from teacher to learner is essentially the transmission of the appropriate response to a certain stimulus. Thus, the point of education is to present the student with the appropriate repertoire of behavioral responses to specific stimuli and to reinforce those responses through an effective reinforcement schedule (Skinner, 1976). Pedagogy, literally translated, is the art or science of teaching children.

Pedagogy is defined by the Oxford Dictionary ("Pedagogy", n.d.) as the method and practice of teaching, especially as an academic subject or theoretical concept, while others prefer to define it as the function or work of a teacher; the art or science of teaching. The word comes from the ancient Greek paidagogos, a compound word comprised of "paidos" (child) and "agogos" (leader). While the term is often used to mean the art of teaching in general, for the sake of accuracy it is preferred to make the distinction between pedagogy (teaching children) and andragogy (teaching adults). Children go through four developmental stages, starting at birth and ending in early adulthood (Yellowhorse, 2014). This is a very important distinction since college and university students are considered beyond the age of childhood, yet they do not possess the life experience to claim the full mantle of adulthood.

A pedagogue is often seen as a schoolteacher. "One who instructs in a pedantic or dogmatic manner" describes Salvatori (1996). In the pedagogic model, teachers assume responsibility for making decisions about what is learned and how and when something will be learned.

Behaviorism is a worldview that assumes a learner is essentially passive, responding to environmental stimuli. The learner starts off as a clean slate (i.e., tabula rasa) and behavior is shaped through positive or negative reinforcement (Watson, 1930). Among the originators and important contributors to this perspective are John B. Watson, Ivan Pavlov, F. Burrhus, B. F. Skinner, E. L. Edward, Thorndike, and Albert Bandura. Skinner (1967) and Watson (1930) are credited with being two of the preeminent pioneering researchers of behaviorist underpinnings in education and learning. Both Skinner and Watson were concerned only with how behavior is affected by external forces, focusing on learning as affected by changes in behavior with no interest in understanding how the human mind functioned; they were behaviorists in the strictest sense. Skinner (1976) espoused that everything human beings do is the result of their experiences. Watson used Pavlov's findings on animal responses to stimuli as a basis for his work (Weegar \& Pacis, 2012). Edward L. Thorndike, a contemporary of Watson, also a noted pioneering researcher in this area, is said to be "perhaps the greatest learning theorist of all time" (Hergenhahn \& Olson, 2005, p. 54).

To accommodate the request of the business community, one of the desired learning outcomes is for students to have the ability to move from theory to practical application - students should be able to take what they have learned and apply it to "real life" situations. Behaviorism does not do well in developing leaners in this area because it cannot cater to all kinds of learning since it disregards mental activities (McHenry et al., 2005). What is commonly regarded as a strength of this learning approach, ensuring that a person behaves in the same way whenever the same circumstance is presented, in practice becomes an impediment to attaining this particular learning outcome. The learners will inevitably find themselves in circumstances where they need to respond, but the mental cues they receive do not match what they have previously been taught (Schuman, 1996). This is a critical weakness when a response requiring critical thinking or an abnormal behavior is needed.

It is apparent that the educational systems' responsible for preparing students to enroll in information technology programs are deeply invested in a pedagogy based on a behaviorist approach. The inability of students to satisfactorily attain learning objectives requiring the ability to think critically is 
a direct result of this. Behaviorist pedagogy does not cultivate analytical or critical thinking because the interactions are teacher dominated (Conner, 2002). Much greater student mental development, which requires heavy student involvement, must be incorporated into their preparation if the desired proficiencies are to be realized. Simply providing an anticipated response to a stimulus is not enough. Complex learning outcomes, in this case application of knowledge to real world situations, are more difficult to evaluate, which renders this teaching methodology insufficient.

When college and university level instruction continues to follow these same pedagogic models, it does a disservice to the learner. Behaviorist teaching methods have proven most successful in areas where there is a "correct" response or easily memorized material; the learner is focused on a clear goal and responds automatically to the signs of that goal. "Limiting the working knowledge of a subject to a finite number of tasks or facts, however, seems misguided in many cases", notes Marcia Conner (2002). A successful program's curriculum must be less didactic and more heuristic; this is a transitionary period for students, and for this reason the behaviorist foundations of their prior learning cannot be completely abandoned. New programs must now move toward being more constructivist in nature with more andragogic influences.

To be effective curriculum must not be so rigid that it does not accommodate a variety of learning styles and situations; conversely it cannot be so adaptable that it appears to have no structure. Altbach, Berdah, and Gumport (2005) advise,

The college curriculum should be flexible in relation to the needs of society inasmuch as higher education serves society at large. Consequently, higher education must provide what society wants. As the needs of society change over time higher education must be prepared to offer new approaches to learning or different teaching methods to fulfill those needs. The curriculum is "dynamic" ... In essence it is a living, breathing organism. It must be permitted to expand, to grow, and to develop. It is not a static thing. It cannot be set in stone. As the world changes so must the curriculum change and continue to be flexible in relation to increasing knowledge bases, the needs of society, and the interests of students and faculty.

As previously mentioned, andragogy purports that adults cannot be taught in the same manner as that used to teach children. Though college students do not have the appropriate amount of life experience or prior knowledge to receive instruction totally based on a constructivist-andragogic approach, they require a more advanced approach than that of a child. Constructivism is heavily dependent on mental processes, such as thinking, memory, knowing, and problem-solving, which are derived from prior knowledge gained through life experience. The most effective approach lies somewhere in between the two paradigms (see Figure 1). Each has its own advantages and disadvantages; the proper balance can be achieved by incorporating the best of both.

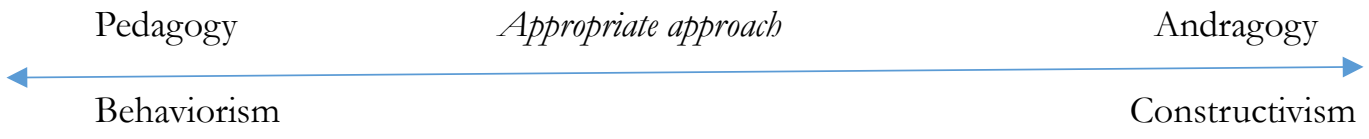

\section{Figure 1. Learning theory continuum}

Constructivist learning theory has proven be to quite effective in producing positive learning outcomes, yet the behaviorist model remains the accepted methodology of content delivery. Even an intermediary move away from behaviorism to cognitivism instead of a complete shift is met with little or no enthusiasm. Continuous assessment and end of academic year exams are realities for all colleges and universities as part of the standard behaviorist-based curriculum. Structure is necessary, but it cannot be so limiting that it absolves the learner from any responsibility for what he or she learns. Both the instructor and the learner have an active role in the education process - neither is passive, nor should they be. 


\section{METHODOLOGY}

The case study research methodology has been selected to conduct the inquiry into this phenomenon. The case study approach was advanced by noted American University scholar-in-residence Robert K. Yin; he is renowned for his work in this area. Yin (2009) explains that this empirical inquiry facilitates exploration of a contemporary phenomenon in depth within its real-life context using a variety of data sources. He instructs that this research design should be considered when (a) the focus of the study is to answer "how" and "why" questions, (b) you cannot manipulate the behavior of those involved in the study, (c) you want to cover contextual conditions because you believe they are relevant to the phenomenon under study, or (d) the boundaries are not clear between the phenomenon and context (Yin, 2003).

Case study research can be exploratory, descriptive, interpretive, and explanatory (Mariano, 1993). For this reason, examining the relationship between learning outcomes and learning theory benefits tremendously from use of the case study approach. It is the purpose of this research to show that the use of improved approaches to learning will produce more desirable learning outcomes; it is therefore deemed to be exploratory in nature. It should also help clarify the unclear boundaries between the occurrence and the context of this phenomenon.

This case study's subject of analysis will be two information technology classes, Management of Information Technology and Operating Systems, composed of a combination of second year and third year students; both classes have six students, the same six students. The study took place during the fall semester of the 2016 school year, which began the first week of August 2016 and ended in late November of the same year. The semester was divided into two halves, each of which was eight (8) weeks in duration; the first half began in August and ended when the mid-term exam was administered. The second half began immediately after the mid-term exam and ended with the taking of the final exam. Both IT classes were conducted during this fall 2016 semester.

Immediately after the classes began in August, the second time classes met, a diagnostic assessment was administered. This pre-test established a baseline of what prior knowledge student's possessed in regard to three specific learning outcomes. The three learning outcomes used as the focus of this research are (1) to have practical skills, understanding principles and theories and being able to apply them efficiently, (2) the ability to integrate knowledge obtained to determine innovative solutions to problems encountered in business using IT, and (3) the ability to analyze problems, understand and be able to integrate knowledge of IT with other relevant disciplines to solve problems.

During the first half of the semester both classes were taught following a curriculum delivered using the traditional methodology, a behaviorist-based pedagogy. Classes were conducted in an "instructorcentric" fashion, that is with very little dialogue and interaction from the students. They fulfilled the role of passive recipients. Lectures, PowerPoint presentations, and assignments were derived from the assigned text to convey subject specific facts, definitions. and theoretical concepts; this first segment culminated with the mid-term exam. The learners were also given a follow-up or interim assessment at this time. This assessment was done to determine the degree to which learning outcomes had been achieved thus far. This also established a second baseline, one that was used with the change to a new instruction delivery methodology.

The second half, which began immediately after the midterm exam, was taught with a modified curriculum that was a combination or blend of the previously used behaviorist based approach incorporating a large amount of constructivist based theory; this methodology had many of the characteristics of an andragogic approach but due to the behaviorist elements still being used was not considered as fully embracing all the tenants of andragogy. These classes were conducted in a much more interactive manner requiring greater participation by students. Scenario based instruction and action learning, an approach to solving real problems that involves taking action and reflecting upon the results, were introduced requiring learners to synthesize theoretical concepts and see them in practical application. During the second half of the semester students were also required to complete a 
project based assignment which was used to demonstrate how well the material covered had been grasped.

A summative assessment was conducted in conjunction with end of semester final exams. This evaluation was used to determine the degree to which learning outcomes had been achieved using the alternative learning methodology. The quality of learning outcome attainment was demonstrated or quantified by the difference between student achievement on the baseline assessment given at the mid-term and student achievement on the summative assessment taken at the end of the semester, which included the final exam.

The diagnostic, interim, and summative assessments were all comprised of a series of scenario based questions requiring the students to synthesize information provided and use prior and or newly acquired knowledge to produce appropriate answers. Students were also interviewed after the courses had been completed to reflect on their learning experiences; their opinions were used to inform how they responded to the introduction of a new means of instruction delivery. Were the students now better able to grasp and maintain the information? Did their increased participation in the learning process stimulate or improve their ability to synthesize information? Were they better equipped to put theory into practical application? The systematic inquiry conducted by this case study research was done to describe and explain this phenomenon and related occurrences.

\section{RESULTS AND DISCUSSION}

This research has been conducted to address the problem that exists between the perceptions of the business and academic communities. Specifically, the business community is dissatisfied with college and university IT program graduates; their opinion is that the majority of the students who complete these programs are not properly prepared to enter the workforce. The question raised deals with the role played by learning theory and teaching approach in learning outcomes; does moving away from pedagogy toward andragogy produce improved learning outcomes? The findings of this inquiry indicate that changing teaching and instructional strategy from a behaviorist-based pedagogy to a more, but not completely, constructivist-based andragogic model results in an improved ability to attain desired learning outcomes and retention of information by students.

At the beginning of the semester a scenario-based diagnostic instrument was used to assess the prior knowledge of the students in the three areas which equate to specific learning outcomes: (1) practical skills understanding principles and theories and the ability to apply them; (2) ability to integrate newly obtained knowledge to develop innovative solutions to problems encountered in business with the use of IT; and (3) ability to understand and analyze problems while integrating knowledge of IT with other relevant disciplines to resolve dilemmas. This pre-test is used to establish the baseline by which improvement is measured; the results for each class from this assessment are displayed in Figures 2 and 3 respectively.

The pre-test instrument for both classes were composed of twenty questions, a combination of multiple choice and short answer essay questions, each worth five points with a maximum total score of one hundred. Some of the questions asked in the Operating Systems course diagnostic mechanism were: a.) What is the difference between an active and a passive entity? b.) Name and describe the seven (7) functions of an operating system. c.) What are the four (4) possible states of a process? How is the data manipulated? d.) From an operating system perspective, what is the difference between a job and a task? A sampling from the Management of Information Technology course diagnostic apparatus questions asked: a.) What is a business strategy? Describe the key positions defined by a business strategy. b.) What are the primary goals of a business in the use of information technology? How does this impact the business model? c.) What is knowledge management? d.) What are the principle methodologies for modeling and designing systems?

After eight (8) weeks of curriculum and instruction, which had been delivered following the traditional "teacher-centric" pedagogic model, an interim assessment that was virtually identical in content 
and composition to that of the diagnostic pre-test was administered to evaluate student progress in attaining the desired learning outcomes. This was also used to establish a secondary baseline which was used for comparative purposes after the second half of the semester was completed. Classroom activities and assignments primarily focused on requiring students to demonstrate their ability to memorize facts, theories, and information while providing programmed responses rather than put the same material into practical application. The mean scores recorded of the aggregate were not very promising with a meager improvement shown over the initial diagnostic. Class 1, the Operating Systems class, the median score on the initial diagnostic was 28 improving to 31 on the interim assessment; the Management of Information Systems initial diagnostic median score was 16.6 increasing to 21 on the interim evaluation. The test results for each class are shown in Figures 2 and 3 respectively.

At this juncture in each of the classes, instructional strategy and teaching methodology were changed. Now rather than using the traditional behaviorist-based pedagogy, a switch was made employing a more constructivist-based andragogic approach. The instructor was no longer the focal point and was no longer fully responsible for how learning took place; the instructor's role became more that of a facilitator motivating students to find solutions by exploring, collaborating, inventing, and experimenting (Fornataro, n.d.). Learning became participatory and greater student involvement was necessary. Classroom exercises and assignments consisted of scenario based instruction and action learning that directly addressed the stated concerns of the business community. In addition to these activities, the students were required to demonstrate their ability to amalgamate theoretical concepts with real world situations by completing a project based assignment; this assignment was used to demonstrate their mastery of the subject matter that has been presented.

A summative evaluation was conducted at the end of the semester which was used to assess student progress in achieving learning outcomes after the introduction of an alternative approach to teaching and learning. Again, the content of this assessment was tantamount to that of the diagnostic and interim instruments previously used to evaluate student progress in attaining the three highlighted learning outcomes. The results from this final assessment for each class are shown in Figures 2 and 3, respectively; they show that student achievement increased considerably. It is extremely noticeable that the scores reflect a definite increase occurred in conjunction with the introduction of the new strategy. It is entirely appropriate to surmise that this improvement was the direct result of the change in methods since all other factors remained unchanged.

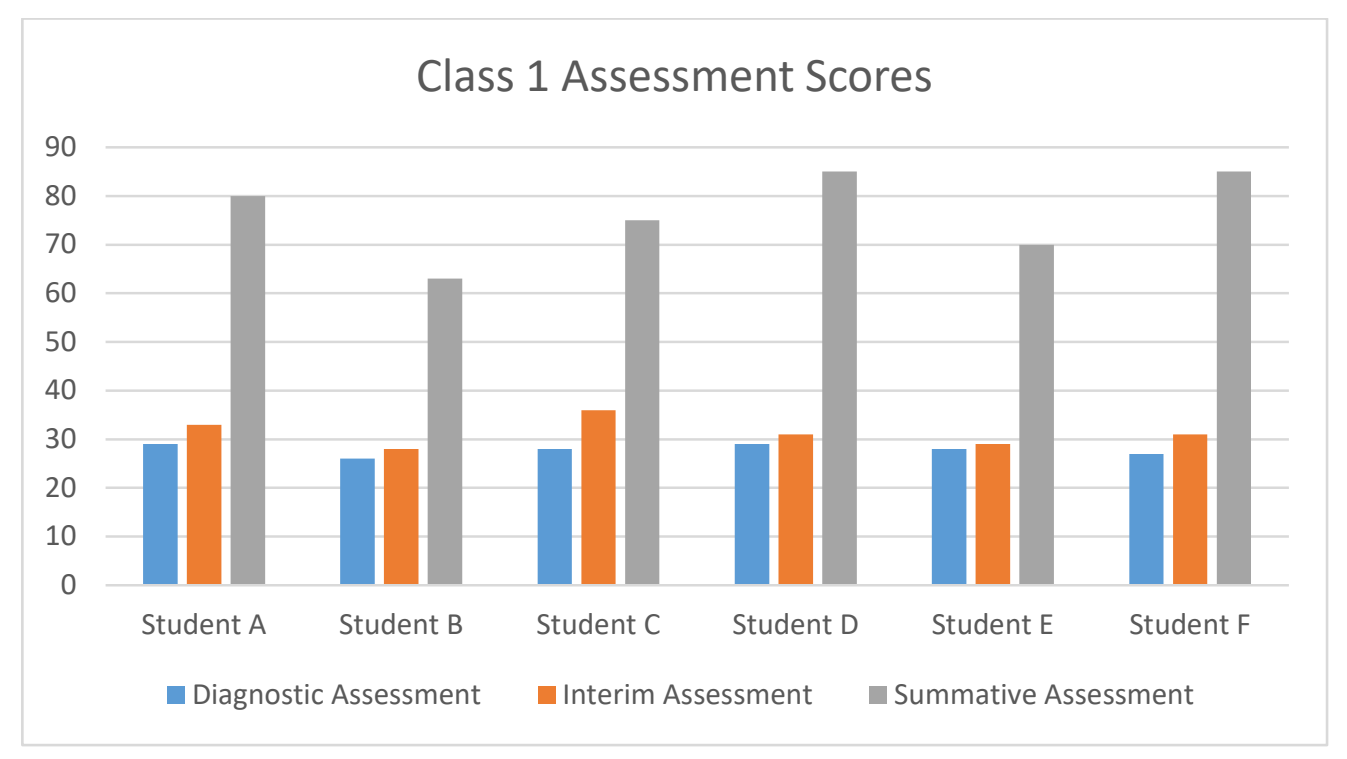

Figure 2. Student Assessment Results from Class 1 


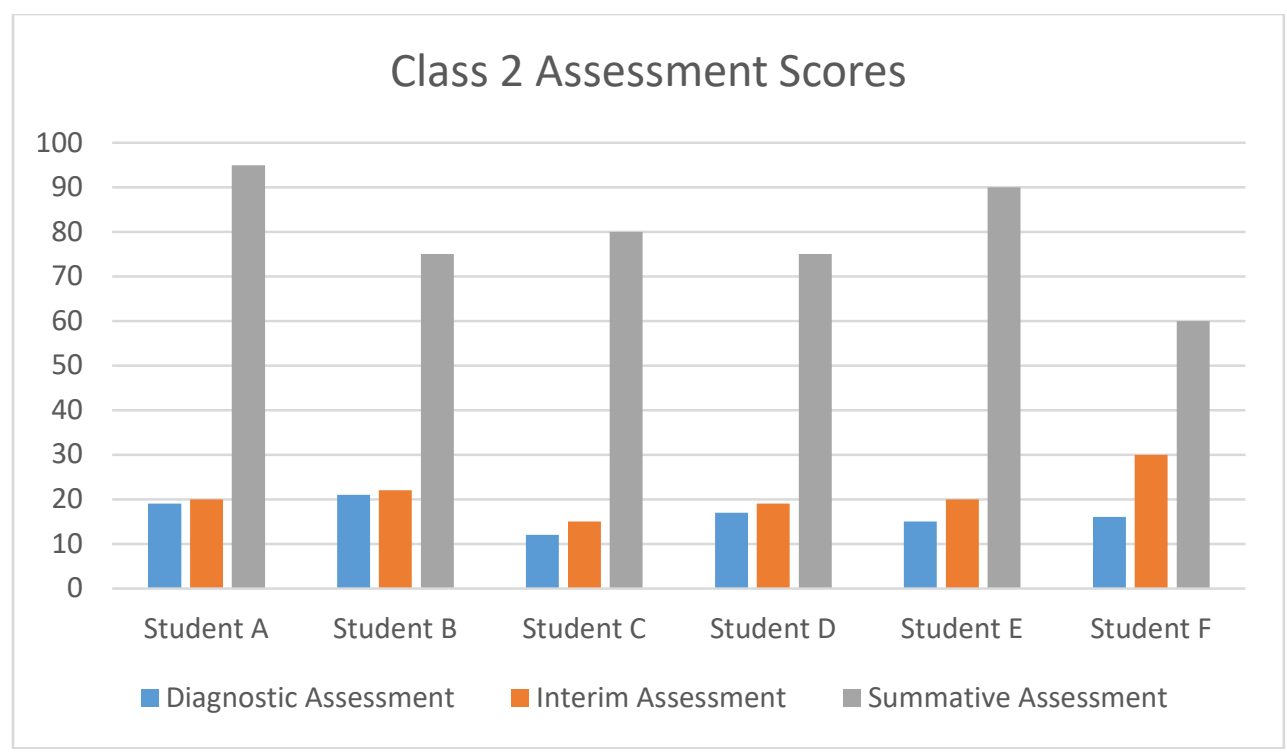

Figure 3. Student Assessment Results from Class 2

The summative evaluation instruments used for both the Operating Systems and the Management of Information Technology classes were conducted using "real-world" scenarios after which students were required to answer essay questions about them. This method allows the students a greater opportunity to more fully demonstrate their mastery of the subject matter and the extent to which learning objectives have been achieved. Figure 4 is an example of one of the Operating Systems class assessment questions asked.

What information is gained from the screen shot below about the structure of the operating system?

\begin{tabular}{|c|c|}
\hline Command Line Tools Console & 㝵因 \\
\hline 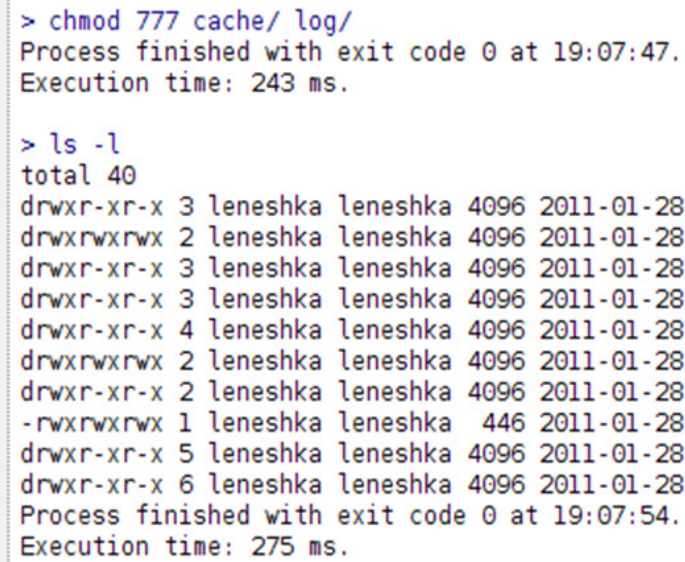 & $\begin{array}{l} \\
18: 59 \text { apps } \\
18: 50 \text { cache } \\
18: 50 \text { config } \\
18: 50 \text { data } \\
18: 50 \text { lib } \\
18: 50 \text { log } \\
18: 50 \text { plugins } \\
18: 50 \text { symfony } \\
18: 50 \text { test } \\
18: 59 \text { web } \\
\end{array}$ \\
\hline
\end{tabular}

Figure 4. Example of a question in the Operating System class

Here is an exemplar of the questions asked in the Management of Information Technology class assessment.

Delta Air Lines Inc. (DAL.N) cancelled hundreds of flights and delayed many others on Monday after an outage hit its computer systems, grounding planes and stranding passengers of one of the world's largest carriers at airports around the globe. The problem occurred 
when the company lost power at its operations center in Atlanta early on the morning of August $8^{\text {th }}$, causing computers needed to book in passengers and fly jets to be down nearly five hours.

The Atlanta-based airline is the second-largest in the U.S. by passenger traffic, initially cancelled 451 flights due to the outage that began around 2:30 a.m. EDT (0630 GMT). Flights gradually resumed about six hours later. The airline eventually cancelled about 1,000 flights on the day of the outage and grounded an additional 1,000 flights over the following two days. As of 1:30 p.m. EDT, it was operating about 1,679 of its nearly 6,000 scheduled flights.

The financial impact was disclosed in a presentation Delta made to investors; the total bill for flight cancellations caused by this devastating computer outage will come to $\$ 150$ million. Delta said passengers booked for travel Aug. 8-12 would be entitled to a refund if their flight is cancelled or significantly delayed. The airline said late Monday it would provide $\$ 200$ in travel vouchers to all customers who experienced a delay of greater than three hours or a cancelled flight as a result of Monday's disruptions.

The disruptions dealt a blow to Delta's efforts to use its recent success in avoiding flight cancellations to win over corporate and leisure customers. Delta is not the only airline to experience these kinds of computer problems recently. With Monday's outage, Delta now joins rivals Southwest Airlines Co (LUV.N) and American Airlines Group Inc. (AAL.O) among airlines that have suffered flight disruptions during the past year due to data system malfunctions. British Airways was also hit with its own problems on Tuesday; the airline didn't give a precise dollar figure, but it is estimated that this incident cost at least $\$ 177$ million in passenger revenue. Industry consultants say airlines face an increasing risk from computer disruptions as they automate more of their operations, distribute boarding passes on smartphones and outfit their planes with Wi-Fi.

- This outage occurred during testing of emergency power system; what measures could the airline have taken to mitigate losses brought about by this system outage?

- What steps should be taken to avert such extensive revenue losses as a result of infrastructure being unavailable in the future?

The results of this inquiry clearly show that the use of the traditional behaviorist based pedagogic model to achieve college and university IT program learning outcomes is not as effective as a more constructivist based andragogic model. It must be pointed out that this newly enacted instructional strategy and teaching methodology is not purely constructivist nor andragogic in nature; it is a hybrid methodology that incorporates necessary elements from behaviorist pedagogy and incorporates constructivist andragogy which has demonstrated itself as being more effective in college and university environments. The pedagogic elements must maintain a presence in the learning environment because constructivism at times calls for the elimination of grades, testing and standardization which is not practical in actual higher education classroom scenarios. Standardized curriculum at this level of education at a minimum generally requires continuous assessments and end of year exams (McHenry et al, 2005).

There are deficiencies in both pedagogic and andragogic methodologies - there is a continuum in which both of these schools of thought are the end points. This explains why instruction based purely on either of these does a disservice to the typical college and university level learner. The correct approach lies somewhere in between them; the most successful outcome attainment would be the product of incorporating the best of both. Structure is necessary but it cannot be overly limiting thereby absolving the learner from their responsibilities in the educational process. Both the instructor and the learner must have an active role in the development of knowledge.

The seminal works of both John Dewey and Malcolm Knowles have proven to be quite valuable in the development of a much needed hybrid model. Knowles is best known for introducing andragogy 
to the academic community. His later research examined the continuum between pedagogy and andragogy producing a model whose level of instructional interaction is optimal at the higher educational level (Fowlkes, 2013). Dewey is thought by many to be one of the most influential thinkers ever in the field of education. "His ideas and approaches to schooling were revolutionary ideas during his lifetime and remain fundamentally important to modern schooling today", espouses educator Adam Jordan (n.d.). Dewey pioneered a methodology referred to as pragmatism which advances the idea that students must interact with their environment in order to adapt and learn. He also believed that teachers and students must learn together (Jordan, n.d.). Both of their approaches appear to be formidable candidates in the quest to fill the void that currently exists between the two aforementioned educational philosophical schools of thought.

John Dewey proposed a hybrid approach where learning is to be a guided experience. He emphasized learning through various activities rather than traditional teacher-focused curriculum. Dewey believed children learned more from guided experience than authoritarian instruction. He ascribed to a learner-focused educational philosophy and therefore held that learning is life not just preparation for life (Conner, 1997). Also, this hybrid approach is intended to make learning be seen as a function of active inquiry and not passive reception.

It is not difficult to understand the correlation between instructional strategy and learning outcomes. Learning and teaching approaches are not "one-size-fits-all" propositions; different strategies are appropriate for different circumstances and situations. Academia has the challenge of moving learners away from one methodology that has been used throughout much of their educational careers to an approach that is better suited to equip them with the skills necessary to meet the challenges awaiting them in the professional world. Based on the opinions expressed by members of the business community, this challenge is not currently being met with widespread success. However, once this undertaking has been accomplished and better learning outcomes are produced their impression of workforce preparedness should improve dramatically.

At the end of the semester when this research was completed, the participants were asked to contribute their thoughts and opinions. Almost all pointed out the observed differences between the first and second halves of the semester. The majority of their responses fell into two general categories: (1) ease of learning and understanding the material covered and (2) better retention of information. Some of their statements were, "The approach used in the second half of the semester made the material easier to grasp ... before midterm we had to memorize everything without putting it into proper context ". Another student remarked, "I will never forget what I learned for as long as I live".

This inquiry was conducted as a first step in addressing a very involved set of circumstances. Instructional strategies produce learning outcomes; learning outcomes demonstrate what knowledge has been acquired. Acquired knowledge is used by students as they pursue professional careers and other ventures in life. It does not claim to be exhaustive, nor does it purport that the same results will occur every time a curriculum turns away from the pedagogic model to a more andragogic one. Further, more comprehensive research in this arena is recommended. This would definitely be a worthwhile venture as it may garner additional improvements allaying the complaints of the business community.

\section{CONCLUSION}

Change is never a simple undertaking. When things have been done a certain way for an extended period of time, they become an accepted practice or the status quo. If asked to move away from the "usual" way of doing things, resistance is to be expected but only until the benefit brought about by change is realized. The academic community is no exception to this fact. Attempts to introduce new learning theories and establish paradigms in the classroom can be a daunting, if not impossible, task. The old "tried and true" method rules the day and is not easily changed; this attitude is unfortunate and sadly is still held by many today. 
The framework of this research and its complementary informing system consist of three elements IT curriculum (informing environment), teaching approach/strategy (delivery system) and learning outcomes (task completion system). It has been shown that the delivery systems currently being used are woefully inadequate and must be changed if the specific problem of addressing improved leaner outcomes is to be accomplished. The behaviorist-based pedagogic approach performs admirably when attempting to build foundational knowledge, but when higher ordered thinking, analysis, and synthesis of information are required, the evidence is clear - another vehicle is necessary. It must be noted that the clientele affected are both the IT academic program students and faculty. The students' performance, as denoted by their ability to attain the desired learning outcomes, is affected by the instruction presented to them via the delivery system employed. The faculty's performance, as demonstrated by their choice of instructional strategy, is also affected by the required change in delivery system. It is therefore reasonable to assert that the methods implemented by instructors and the students' ability to successfully secure the desired learning outcomes must be and are the focal point of change. A shift toward a more constructivism-based andragogic model has demonstrated that it can provide improvement.

Undergraduate college and university IT program students have, for the majority of their prior educational years, received instruction based on a behaviorist pedagogical. This type of approach is effective in creating a foundation for the knowledge of these 18 to 23 years old, but does not do well when analytical or critical thinking skills need to be developed. Desired learning outcomes at this level of education are more complex and require a departure from the traditional teaching methodologies that they have been the recipients of. This circumstance is further complicated by the fact that this is now a transitional period for these students; they must become more active participants in the educational process yet they still require some level of direction and guidance. Finding the proper balance can be complicated but a hybrid methodology provides a potential avenue to improving learner performance and their ability to achieve better outcomes.

University and college level IT programs must find new avenues to support their quest to improve learning outcome attainment from their students. Greater emphasis must now be placed on the learner; the role of instruction must move away from being 'teacher-focused'. This inquiry explores how developing and using an alternative methodology can produce results.

Improved learning outcomes, particularly in the areas requiring practical application of theory, ability to analyze problems and integrate knowledge to develop solutions, will produce IT program graduates who are better equipped to deal with the challenges faced in the current business environment. This in turn should facilitate a more positive opinion from the business community of the job being done by higher education to prepare the future workforce.

\section{REFERENCES}

Altbach, P., Berdah, R., \& Gumport, P. (2005). American higher education in the twenty-first century (2nd ed.). Baltimore, MD: John Hopkins University Press.

Boumová, V. (2008). Traditional vs. modern teaching methods: Advantages and disadvantages of each. Retrieved from https://is.muni.cz/th/86952/ff m b1/MgrDiplomkaBoumova.pdf

Conner, M. (2002). A primer on educational psychology. Retrieved from http://marciaconner.com/resources/edpsych/

Fischer, K. (2013). The employment mismatch. The Chronicle of Higher Education. Retrieved from http://www.chronicle.com/article/The-Employment-Mismatch/137625/\#maincontent

Fornataro M. (n.d.). Comparing and contrasting constructivism and behaviourism. Retrieved from http://home.earthlink.net/ moodybeatle/compare.html

Fowlkes, J. (2013, July). A new bybrid design model: Synergizing the works of Bloom and Knowles. Paper presented at Annual Sloan Consortium Blended Learning Conference and Workshop, Milwaukee, WI. 
Hergenhahn, B., \& Olson, M. (2005). An introduction to theories of learning. Upper Saddle River, NJ: Pearson Prentice Hall.

Jordan, A. (n.d.). John Dewey on education: Impact \& theory. Retrieved from http://study.com/academy/lesson/john-dewey-on-education-impact-theory.html\#transcriptHeader

Mariano, C. (1993). Case study: The method. In P. Munhall \& C. Oiler Boyd (Eds.), Nursing research: A qualitative perspective (pp. 311-337). New York: National League for Nursing Press.

McHenry, A., Depew D., Dyrenfurth, M., Dunlap, D., Keating, D., Stanford, T.,...Deloatch, G.. (2005). Constructivism: The learning theory that supports competency development of engineers for engineering practice and technology leadership through graduate education. Proceedings of the 2005 American Society for Engineering Education Annual Conference \& Exposition.

Pedagogy. (n.d.). Oxford Dictionary. Retrieved from https://en.oxforddictionaries.com/definition/pedagogy

Richards, J. (2006). Communicative language teaching today. New York, NY: Cambridge University Press

The role of higher education in career development: Employer perceptions. (2012). Chronicle of Higher Education and America's Public Media's Marketplace. Retrieved from http://www.chronicle.com/items/biz/pdf/Employers\%20Survey.pdf

Salvatori, M. (1996). Pedagogy: Disturbing history, 1820-1930. Pittsburgh, PA: University of Pittsburgh Press.

Schuman, L. (1996). Perspectives on instruction. Retrieved from http://edweb.sdsu.edu/courses/edtec540/Perspectives/Perpectives.htm .

Skinner, B. F. (1976). About behaviorism. New York: Vintage Books

Watson, J. (1930). Behaviorism. Chicago, IL: University of Chicago Press.

Weegar, M., \& Pacis, D. (2012). A comparison of two theories of learning: Behaviorism and constructivism as applied to face-to-face and online learning. In Proceedings E-Leader Conference, Manila. Retrieved from https://www.g-casa.com/conferences/manila/papers/Weegar.pdf

Yellowhorse, H. (2014). Learning approaches, theory, and practice. Retrieved from https://prezi.com/fdf77qh6lgyx/learning-approaches-theory-and-practice/

Yin, R. (2003). Case Study Research: Design and Methods (3 ${ }^{\text {rd }}$ ed.). Thousand Oaks, CA: Sage Publications.

Yin, R. (2009). Case Study Research: Design and Methods (4 ${ }^{\text {th }}$ ed.). Thousand Oaks, CA: Sage Publications.

\section{BIOGRAPHY}

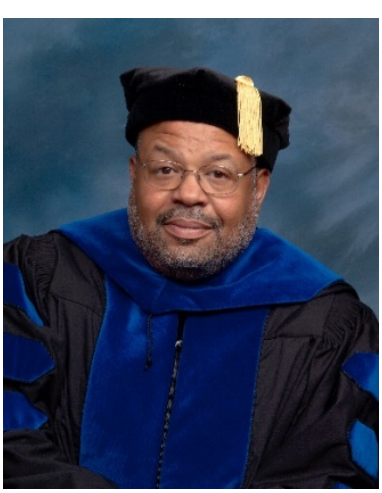

Dr. Derrick L. Anderson worked as an IT professional for over 30 years before transitioning into higher education on a full time basis. Experiences and observations made during his many years as a practitioner motivated him to pursue and earn his doctorate in Information Technology with a specialization in Education; he is extremely interested in bridging the chasm that exists between the interests of the academic and business communities. 